Research Paper

\title{
THE CLEAN DEVELOPMENT MECHANISM (CDM) PROCE- DURE AND IMPLEMENTATION IN VIETNAM
}

\author{
Mai Hai Tung ${ }^{1}$
}

\section{ARTICLE HISTORY}

Received: August 20, 2019 Accepted: September 15, 2019

Publish on: October 25, 2019

\section{ABSTRACT}

The Clean Development Mechanism (CDM) allows a country with an emission-reduction or emission-limitation commitment under the Kyoto Protocol (Annex B Party) to implement an emission-reduction project in developing countries. The mechanism stimulates sustainable development and emission reductions, while giving industrialized countries some flexibility in how they meet their emission reduction or limitation targets. Under the CDM, there are various benefits, enormous potential to promote sustainable development and increase foreign investment flows for developing countries. With thoughtful planning and the development of a national CDM strategy, it can also assist in addressing local and regional environmental problems and in advancing social goals. With the support of developed countries, Vietnam not only can achieve long-term sustainable development but also be able to play a role in climate protection.

Keywords: Clean Development Mechanism (CDM), United Nations Framework Convention on Climate Change (UNFCCC), The Kyoto Protocol.

\section{Introduction}

The Clean Development Mechanism (CDM), a cooperative mechanism established under the Kyoto Protocol, has the potential to assist devel- oping countries in achieving sustainable development by promoting environmentally friendly investment from industrialized country governments and businesses. While the basic rules have been established, the CDM is a work in progress by participating governments.

The 1997 Kyoto Protocol, a milestone in global efforts to protect the environment and achieve sustainable development, marked the first time that governments accepted legallybinding constraints on their greenhouse gas emissions. The Protocol also broke new ground with its innovative "cooperative mechanisms" aimed at cutting the cost of curbing these emissions. The Protocol includes three market-based mechanisms aimed at achieving cost-effective reductions - International Emissions Trading (IET), Joint Implementation (JI), and the CDM.

The CDM, contained in Article 12 of the Kyoto Protocol, allows governments or private entities in industrialized countries to implement emission reduction projects in developing countries and receive credit in the form of "certified emission reductions" or CERs (UNEP, 2017).

\subsection{International agreement}

\subsubsection{The UNFCCC\& the Kyoto Protocol}

The United Nations General Assembly published by formally launching negotiations on a framework convention on climate change and establishing an "Intergovernmental Negotiating Committee" to develop the treaty. Negotiations

\section{$\triangle$ Mai Hai Tung}

Corresponding author: haitung88@gmail.com

${ }^{1}$ Science, Technology and International Cooperation Department, Vietnam Meteorological and Hydrological Administration, Hanoi, Vietnam 
to formulate an international treaty on global climate protection began in 1991 and resulted in the completion, by May 1992, of the United Nations Framework Convention on Climate Change (UNFCCC) (Hoang et al., 2014).

\subsubsection{The United Nations Framework Con-} vention on Climate Change (UNFCCC)

The UNFCCC was opened for signature at the UN Conference on Environment and Development (the Earth Summit) in Rio de Janeiro, Brazil, in June 1992, and entered into force in March 1994. The Convention sets an "ultimate objective" of stabilizing atmospheric concentrations of greenhouse gases at safe levels. To achieve this objective, all countries have a general commitment to address climate change, adapt to its effects, and report their actions to implement the Convention. As of December 2001, the Convention currently has received 186 instruments of ratification (UNEP, 2017).

More than 150 countries signed in June 1992 in Rio de Janeiro (Brazil) (Hoang et al., 2014). The Convention divides countries into two groups: Annex I Parties, the industrialized countries who have historically contributed the most to climate change, and non-Annex I Parties, which includes primarily the developing countries (UN, 2009).

\subsubsection{The Kyoto Protocol}

The Kyoto Protocol was adopted in December 1997. The Protocol creates legally binding obligations for 38 industrialized countries, including 11 countries in Central and Eastern Europe, to return their emissions of GHGs to an average of approximately 5.2 percent below their 1990 levels as an average over the period 20082012.

The targets cover the six main greenhouse gases: carbon dioxide, methane, nitrous oxide; hydrofluoro-carbons (HFCs); perfluoro-carbons (PFCs); and sulphur hexafluoride (Hoang et al., 2014). The Protocol also allows these countries the option of deciding which of the six gases will form a part of their national emissions reduction strategy. Some activities in the land-use change and forestry sector, such as deforestation and reforestation, that emit or absorb carbon dioxide from the atmosphere, are also covered (Hieu, 2003).

\subsubsection{The Clean Development Mechanism} (CDM) and the Cooperative Mechanisms

The Protocol establishes three cooperative mechanisms designed to help industrialized countries (Annex I Parties) reduce the costs of meeting their emissions targets by achieving emission reductions at lower costs in other countries than they could domestically International Emission Trading permits countries to transfer parts of their "allowed emissions" ("assigned amount units").

Joint Implementation (JI) allows countries to claim credit for emission reductions that arise from investment in other industrialized countries, which result in a transfer of equivalent "emission reduction units" between the countries (UNEP, 2017).

The Clean Development Mechanism (CDM) allows emission reduction projects that assist in creating sustainable development in developing countries to generate "certified emission reductions" for use by the investor.

The mechanisms give countries and private sector companies the opportunity to reduce emissions anywhere in the world wherever the cost is lowest and they can then count these reductions towards their own targets.

Through emission reduction projects, the mechanisms could stimulate international investment and provide the essential resources for cleaner economic growth in all parts of the world. The CDM, in particular, aims to assist developing countries in achieving sustainable development by promoting environmentally friendly investment from industrialized country governments and businesses.

The funding channelled through the CDM should assist developing countries in reaching some of their economic, social, environmental, and sustainable development objectives, such as cleaner air and water, improved land use, ac- 
companied by social benefits such as rural development, employment, and poverty alleviation and in many cases, reduced dependence on imported fossil fuels. In addition to catalyzing green investment priorities in developing countries, the CDM offers an opportunity to make progress simultaneously on climate, development, and local environmental issues. For developing countries that might otherwise be preoccupied with immediate economic and social needs, the prospect of such benefits should provide a strong incentive to participate in the CDM.

\subsection{Overview of CDM}

\subsubsection{Participation}

The CDM allows an Annex I Party to implement a project that reduces greenhouse gas emissions or, subject to constraints, removes greenhouse gases by carbon sequestration, or "sinks," in the territory of a non-Annex I Party. The resulting certified emission reductions, known as CERs, can then be used by the Annex I Party to help meet its emission reduction target. CDM projects must be approved by all Parties involved, lead to sustainable development in the host countries, and result in real, measurable and long-term benefits in terms of climate change mitigation. The reductions must also be additional to any that would have occurred without the project (UNEP, 2017).

In order to participate in the CDM, there are certain eligibility criteria that countries must meet. All Parties must meet three basic requirements: voluntary participation in the CDM, the establishment of a National CDM Authority, and ratification of the Kyoto Protocol. In addition, industrialized countries must meet several further stipulations: establishment of the assigned amount under Article 3 of the Protocol, a national system for the estimation of greenhouse gases, a national registry, an annual inventory, and an accounting system for the sale and purchase of emission reductions.

\subsubsection{Eligible Projects}

The CDM will include projects in the follow- ing sectors: End-use energy efficiency improvements, Supply-side energy efficiency improvement, Renewable energy, Fuel switching, Agriculture (reduction of $\mathrm{CH}_{4}$ and $\mathrm{N}_{2} \mathrm{O}$ emissions), Industrial processes $\left(\mathrm{CO}_{2}\right.$ from Cement etc., $\mathrm{HFC}_{\mathrm{s}}, \mathrm{PFC}_{\mathrm{s}}, \mathrm{SF}_{6}$ ), Sinks projects (only afforestation and reforestation).

In order to make small projects competitive with larger ones, the Marrakech Accords establish a fast track for small-scale projects with simpler eligibility rules-renewables up to $15 \mathrm{MW}$, energy efficiency with a reduction of consumption either on the supply or the demand side of up to 15 giga watt hours/yr, and other projects that both reduce emissions and emit less than 15 kilotons of $\mathrm{CO}_{2}$ equivalent annually.

\subsubsection{Financing}

Public funding for CDM projects must not result in the diversion of funds for official development assistance. In addition, the CERs generated by CDM projects will be subject to a levy-known as the "share of the proceeds" of $2 \%$, which will be paid into a newly-created adaptation fund to help particularly vulnerable developing countries adapt to the adverse effects of climate change.

Another levy on CERs will contribute to the CDM's administrative costs. To promote the equitable distribution of projects among developing countries, CDM projects in least developed countries are exempt from the levy for adaptation and administrative costs.

\subsubsection{The Executive Board}

The CDM is supervised by an Executive Board, which itself operates under the authority of the Parties. The Executive Board is composed of10 members, including one representative from each of the five official UN regions (Africa, Asia, Latin America and the Caribbean, Central and Eastern Europe, and OECD), one from the small island developing states, and two each from Annex I and non-Annex I Parties.

The Executive Board will accredit independent organizations-known as operational entities that will validate proposed CDM projects, ver- 
ify the resulting emission reductions, and certify those emission reductions as CERs. Another key task is the maintenance of a CDM registry, which will issue new CERs, manage an account for CERs levied for adaptation and administrative expenses, and maintain a CER account for each non-Annex I Party hosting a CDM project.

\subsubsection{Project Identification and Formulation}

The first step in the CDM project cycle is the identification and formulation of potential CDM projects. A CDM project must be real, measurable and additional. To establish additionality, the project emissions must be compared to the emissions of a reasonable reference case, identified as the baseline. The baseline is established by the project participants according to approved methodologies on a project specific basis. These baseline methodologies are being developed based on the three approaches in the Marrakech Accord.

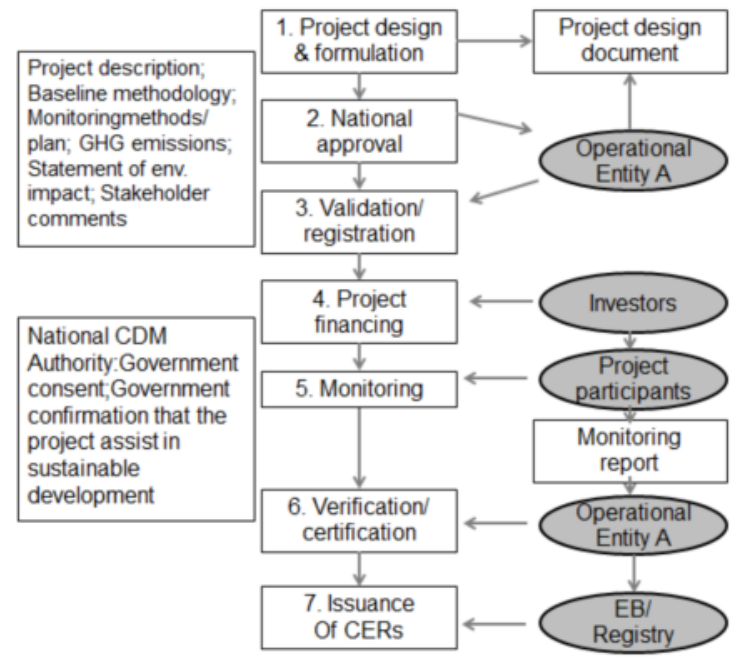

Fig. 1. Viet Nam - Key Country Indicators (UNEP, 2017)

The CDM project cycle as shown on the figure has seven basic stages: project design and formulation, national approval, validation and registration, project finance, monitoring, verification/certification and issuance of CERs. The first four are performed prior to the implementation of the project, while the latter three are performed during the lifetime of the project.

CDM projects must also have a monitoring plan to collect accurate emissions data. The monitoring plan, which constitutes the basis of future verification, should provide confidence that the emission reductions and other project objectives are being achieved and should be able to monitor the risks inherent to baseline and project emissions. The monitoring plan can be established either by the project developer, or by a specialized agent. The baseline and monitoring plan must be devised according to an approved methodology.

\subsubsection{National Approval}

All countries wishing to participate in the CDM must designate a National CDM Authority to evaluate and approve the projects, and serve as a point of contact. Although the international process has given general guidelines on baselines and additionality, each developing country has the responsibility to determine the national criteria for project approval. Together with the investor, the host country must prepare a project design document with the following structure: General description of the project; Description of the baseline methodology; Timeline and crediting period; Monitoring methodology and plan; Calculation of GHG emissions by sources; Statement of environmental impacts; Stakeholder comments.

\subsubsection{Validation and Registration}

A designated operational entity will then review the project design document and, after public comment, decide whether or not it should be validated. These operational entities will typically be private companies such as auditing and accounting firms, consulting companies and law firms capable of conducting credible, independent assessments of emission reductions. If validated, the operational entity will forward it to the Executive Board for formal registration.

\subsubsection{Monitoring, Verification and Certifica-} tion

The carbon component of a mitigation project cannot acquire value in the international carbon market unless submitted to a verification process designed specifically to measure and audit the 
carbon component. Therefore, once the project is operational, participants prepare a monitoring report, including an estimate of $\mathrm{CER}_{\mathrm{s}}$ generated, and submit it for verification by an operational entity. Verification is the independent ex-post determination by an operational entity of the monitored reductions in emissions.

\subsection{National Value and Benefits}

The basic principle of the CDM is simple: developed countries can invest in low-cost abatement opportunities in developing countries and receive credit for the resulting emissions reductions, thus reducing the cutbacks needed within their borders. While the CDM lowers the cost of compliance with the Protocol for developed countries, developing countries will benefit as well, not just from the increased investment flows, but also from the requirement that these investments advance sustainable development goals. The CDM encourages developing countries to participate by promising that development priorities and initiatives will be addressed as part of the package. This recognizes that only through long-term development will all countries be able to play a role in protecting the climate (UNEP, 2017).

From the developing country perspective, the CDM can: Attract capital for projects that assist in the shift to a more prosperous but less carbonintensive economy; Encourage and permit the active participation of both private and public sectors; Provide a tool of technology transfer, if investment is channelled into projects that replace old and inefficient fossil fuel technology, or create new industries in environmentally sustainable technologies; and, Help define investment priorities in projects that meet sustainable development goals.

Specifically, the CDM can contribute to a developing country's sustainable development objectives through: Transfer of technology and financial resources; Sustainable ways of energy production; Increasing energy efficiency \& conservation; Poverty alleviation through income and employment generation; and Local environ- mental side benefits.

The drive for economic growth presents both threats and opportunities for sustainable development. While environmental quality is an essential element of the development process, in practice, there is considerable tension between economic and environmental objectives. Increased access to energy and provision of basic economic services, if developed along conventional paths, could cause long-lasting environmental degradation both locally and globally. But by charting a different course and providing the technological and financial assistance to follow it, many potential problems could be avoided.

\subsection{Developing a National CDM Strategy}

\subsubsection{Evaluation of National Interests and}

\section{Priorities}

The CDM presents an opportunity to channel resources towards the projects that are most likely to further national sustainable development. Criteria for CDM projects should therefore be based on a country's sustainable development objectives, which may be identified by the goals and policies already established for social and economic development in related areas, such as energy, land-use change and transportation. At the national level, sustainable development programs or environmental plans may already be in place in related areas, such as policies on forests, renewable energy and clean technologies (MFAD, 2009).

\subsubsection{Building Support for CDM - A Partic-} ipatory Approach

One of the most challenging aspects of building a national CDM strategy is enlisting the active support from all sectors of society (civil, NGOs, private and public sector) and different sectors of the economy (industry, energy, agriculture, forestry). A successful CDM strategy will require official governmental support, both in terms of ratification of the UNFCCC and the Kyoto Protocol, but also in designating a National Authority to approve CDM projects. However, governments will also play a key role in 
cooperating with the private sector to market the CDM proposals to prospective investors.

The private sector can help ensure an emphasis on efficiency and the development of clear and simple rules. Including the participation of the private sector in the institutional building process encourages a less bureaucratic and more results-oriented approach in the procedure. The private sector is essential for driving the CDM, as investors seek cost-efficient means of mitigating their emissions.

Non-governmental organizations (NGOs) should also be incorporated in the development and implementation of the strategy, since they bring an environmental and social focus to the institutional agenda. NGOs can be repositories of valuable scientific expertise and technical know-how in developing and evaluating projects.

1.4.3. National Institutional Structure to Implement CDM Projects

The National CDM Authority is the host country entity or body that evaluates potential $\mathrm{CDM}$ projects and provides written approval confirming that the project activity is voluntary, complies with national and international criteria, and assists in achieving sustainable development of the host country (UNEP, 2017).

The National CDM Authority needs to have open communication with the government agencies of the sectors relevant to the CDM. The technical review of projects can often involve the ministries or bureaus of the relevant sector (energy, natural resources, environment, etc.).The approval of CDM projects could also involve foreign affairs ministries, since they often serve as the UNFCCC focal point.

\subsubsection{Evaluation and Approval}

The process will increase the probability of having projects successfully validated and certified as CDM projects, and reduce the perceived and real risks of national and foreign investors in developing and implementing carbon mitigation projects. It can also create incentives for specific project types or for priority sectors. The evaluation process also provides the main filter for ensuring that projects pursue CDM objectives consistent with relevant national policies, strategies and priorities.

International criteria: As a starting point in the evaluation process, a CDM project must first satisfy the internationally agreed criteria. Article 12 of the Kyoto Protocol stipulates three principal eligibility criteria for CDM projects:

- Projects must assist Non-Annex I Parties "in achieving sustainable development and contributing to the ultimate objective of the Convention".

- Projects must result in "real, measurable and long-term benefits related to the mitigation of climate change".

- Projects must result in "reductions in emissions that are additional to any that would occur in the absence of the certified project activity".

1.4.5. Project Supply, Identification and Formulation

To promote CDM investment, host countries can hold training sessions for project developers, during which they are shown how to identify potential projects, understand the context of the UNFCCC and the carbon market, and familiarize themselves with the PDD (UNEP, 2017). Training sessions may also be necessary to understand the more complex aspects of CDM projects, such as generating proper documentation for the establishment of baselines (including assumptions and methodologies used), as well as calculating project emissions, reductions and leakage; that is, the indirect effect of emission reduction projects that lead to arise in emissions elsewhere (UNFCCC, 2018).

2. The clean development mechanism implementation in Vietnam

2.1. Introduction of policy and strategy of implementing CDM in Vietnam

Vietnam ratified UNFCCC on 16 November 1994 and signed Kyoto Protocol (KP) on 3 December 1998 and ratified on 25 September 2002. Ministry of Natural Resources and Environment (MONRE) is assigned by the Government as a 
National Authority to implement UNFCCC and KP (MONRE, 2019). Submitted first national communication to UNFCCC in November 2003. The project: "Capacity Development for the Clean Development Mechanism in Viet Nam", phase 2 was carried out in Viet Nam in 2003 with 6 main tasks. International Cooperation Department, MONRE is a Executing Agency to coordinate and carry out the project (Hoang et al., 2014).

Vietnam government set up several objectives: Task 1: Public information for raising CDM awareness; Task 2: Capacity development on CDM for policy makers; Task 3: Establishment and capacity development for CDM National Authority (CNA); Task 4: Capacity development for stakeholders relevant to CDM projects; Task 5: Capacity building on CDM research and education; Task 6: Creating a pipeline of CDM eligible projects.

\subsubsection{Legal Framework}

Legal documents issued by Prime Minister: Directive No. 35/2005/CT-TTg dated 17 October 2005 on the implementation of KP to the UNFCCC; Decision No. 47/2007/QD-TTg dated 06 April 2007 on approving KP implementing plan to the UNFCCC; Decision No. 130/2007/QD-TTg dated 02 August 2007 on a number financial mechanisms and policies for CDM projects (Financial Policy Circular, 2007).

Legal documents issued by MONRE and MOF: Joint-Circulars No. 58/2008/TTLT-BTCBTNMT dated 04 July 2008 for guiding the implementation of some articles in Decision 130/2007/QD-TTg dated 02 August 2007 (Financial Policy Circular, 2007). Joint-Circulars No.204/2010/TTLT-BTC-BTN\&MT dated $15 / 12 / 2010$ to complement for Joint-Circulars No. 58/2008/TTLT-BTC-BTNMT.

Legal documents issued by MONRE: MONRE has issued Circulars No. 12/2010/TTBTNMT dated 26 July 2010 (replacing Circular No. 10/2006/TT-BTNMT dated 12 December 2006) and Circulars No. 15/2011/TT-BTNMT dated 28 April 2011 on guiding the devel- opment of CDM projects under KP in Viet Nam. Circulars No. 15/2014/TT-BTNMT dated 24 March 2014 on guiding the development of CDM projects underKP in Viet Nam (replacing Circulars No. 15/2011/TT-BTNMT dated 28 April 2011).

\subsubsection{CDM's Institutional Arrangement}

In order to govern and manage efficiently, CDM's Institutional Arrangement is set up to create good CDM plan and help project developers in development.

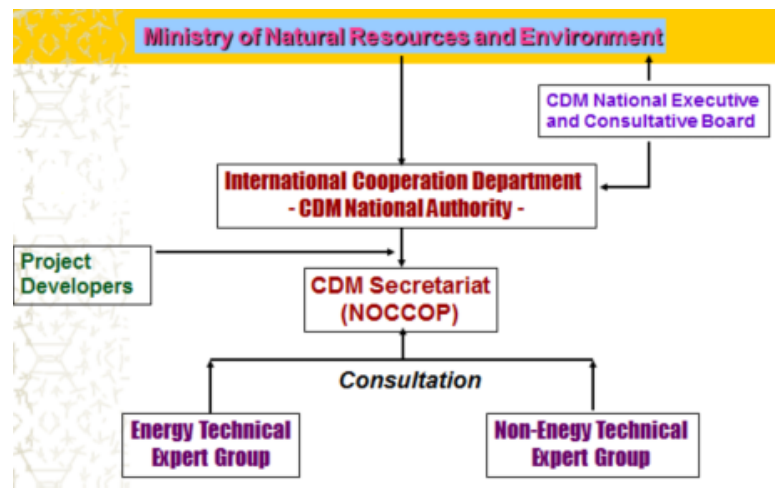

Fig. 2. CDM's Institutional Arrangement (Hieu, 2003)

\subsubsection{Approval Procedure for CDM Project}

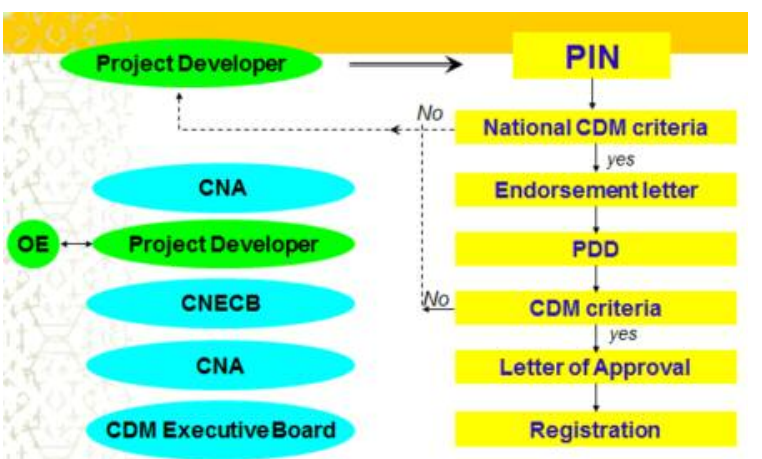

Fig. 3. Approval Procedure for CDM Project (Hieu, 2003)

According to the Circulars issued by MONRE, a document application for LoA of PDD/ PoA-DD in Viet Nam has to include (Tuan, 2012): 1) PDD, PoA-DD, CPA-DD developed by project participants; 2) Letter submitted by CDM project developers to Viet Nam DNA for LoA; 3) Comments of stakeholders directly affected by project activities; 4) The approved environmental impact assessment report; 
5) The other related licenses (if any) provided by competent authorities for projects in specific fields under current regulations; 6) Technical report for PDD or PoA-DD validation report of a DoE; 7) The authorization letter of foreign investor to domestic investor for executing the obligations on registration and CER fee payment if foreign investors did not have representative office in Viet Nam.

Moreover, Preparation for CDM projects are also presented in legal official circulars such as CDM project developers shall formulate CDM project documents on the basis of investor's requirements by either of the following methods: Formulate PIN, submit it to a competent authority for grant of letter of endorsement, and then continue to formulate PDD or PoA-DD together with general CPA-DD and practical CPA-DD. Formulate PDD or PoA-DD together with general CPA-DD and practical CPA-DD, then submit them to a competent authority for grant of letter of approval.

\subsubsection{Remarks}

For electricity generation projects, the emission factor for electricity published by DMHCC is used in PDD/PoA-DD. If the project connects to the national power grid, it needs the support letter from Electricity of Viet Nam (EVN). For the hydropower project, it needs the license for using water surface; For the wastewater treatment project, it needs the license for releasing wastewater into the river. For multi-country PoA, it needs the LoA of the host country.

\subsection{CDM potential projects, Implementa-} tion CDM in Vietnam and Current affairs

\subsubsection{CDM project cycle}

Requirements for CDM projects in Viet Nam: CDM project investors and developers implement and develop CDM project based on voluntary and have to follow current regulations; GHG emission reduction; Appropriate with national and local socio-economic development programmes and strategies; Contribute to sustainable development of Viet Nam; Ensure the feasibility with advance technology and have suitable financial sources; The amount of GHG emission is reality, have additionality, is calculated and verified directly or indirectly; Have environmental impact assessment; Have support from stakeholders; Have approval of host country; Register with EB and have its approval; The implementation of CDM projects do not lead to arise any new responsibilities for Vietnamese Government to KP content.

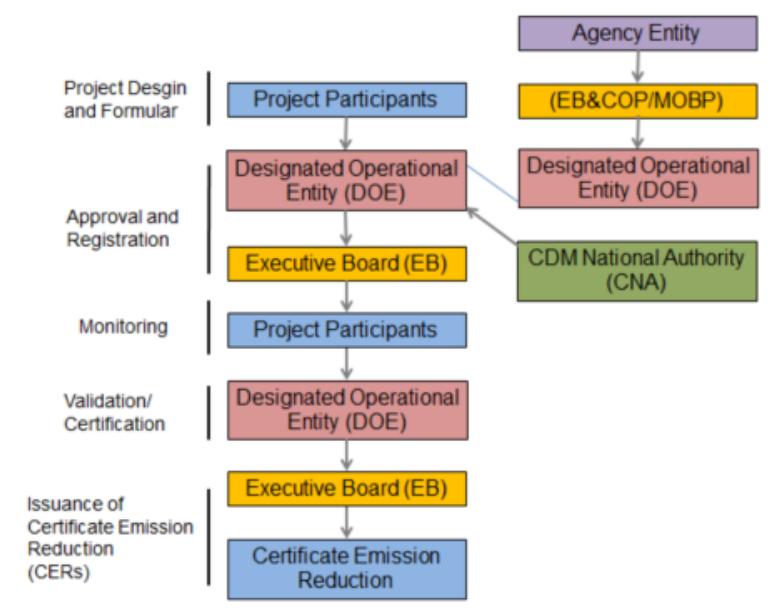

Fig. 4. CDM project cycle (Hieu, 2003)

Main activities and results of implementation of UNFCCC

Vietnam has carried out the following climate change projects (Hoang et al., 2014): 1) Asian: Study on global impacts of climate change; 2) "Asian Least Cost GHG Abatement Strategy" (ALGAS); 3) Vietnam coastal zone vulnerability assessment; 4) Economic of GHG Limitation (Phase 1): "Formulization of methodology to assess GHG limitation"; 5) Reduction of electricity consumption in Cement Ha Tien 2 Plant by using surplus thermal for additional generation; 6) Implementation of UNFCCC in Quang Ninh Province; 7) "Enabling Activities for the Preparation of Initial National Communication Related to UNFCCC"; 8) "Vietnam National Strategy Study on Clean Development Mechanism" (NSS); 9) Use of biogas; 10) Increasing carbon sequestration in planted forest in Vietnam through use of genetically improved species; 11) Energy efficient in Public Lighting sector.

2.2.2. Formulation and development of climate change, CDM/PCF projects portfolio: 
Improve energy efficiency in Small Medium Scale Enterprises (SME); Reducing CH4 emission by managing water level on rice fields. Fuel switching oil to gas (Thu Duc Plant); Recover CH4 from landfills (Ho Chi Minh City, Ha Noi, Hai Phong City). Capacity Development for CDM; Development of renewable energies (wind, biogas, solar, geothermal power); Cogeneration of electricity (Nghe An Tate \& Lyle Company); Establishment of Protection Forest (Central Regional).

The project has launched by UNEP with the support from Dutch Government. Vietnam is one of the three countries in Asia has been selected to participate in the project. The project will assist Viet Nam to take advantages to joint CDM market through establishing GHG emission reduction projects that are consistent with national sustainable development goals.

Expected Outcomes: Define and improve a regulatory framework to support CDM activities;
Enhance CDM capacity building and skills for related organizations; Identify prospective CDM projects; Operational information and guidelines for raising awareness and capacity building on CDM that can be applied in the project (Laurie, 2018).

Project Preparation Phase: Review national experiences on AIJ / CDM projects; Organize and participate in CDM national workshop with participation of main national stakeholders involved on CDM; Establish a country specific strategy approach in order to obtain the highest degree of political support; Designate an appropriate focal point agency that will coordinate national CDM activities and investments; Develop a multi-year work plan for promoting nationals CDM activities and investments in Vietnam.

\subsubsection{CDM projects under consideration}

It is witnessed a gradually rise number of registration of CDM projects in Vietnam, especially hydropower projects.

Table 1. Potential CDM projects under consideration

\begin{tabular}{|c|c|c|c|c|}
\hline No & Name of Project & $\begin{array}{l}\text { Project } \\
\text { site }\end{array}$ & $\begin{array}{c}\text { Emission reduction } \\
\text { potential } \\
\left.(\mathrm{Gg} \mathrm{CO})_{2}\right) \\
\end{array}$ & Status \\
\hline 1 & $\begin{array}{l}\text { Rang Dong oil field associated gas } \\
\text { recovery utilization }\end{array}$ & Vung Tau City & 6,740 & Approval letter \\
\hline 2 & $\begin{array}{l}\text { Thuong Ly landfill closure and gas } \\
\text { recovery and utilization }\end{array}$ & Hai Phong City & 64 & Endorsement letter \\
\hline 3 & $\begin{array}{l}\text { Ho Chi Minh/Hanoi Cities landfill } \\
\text { gas for electricity generation }\end{array}$ & HCM/Hanoi Cities & 3,100 & Endorsement letter \\
\hline 4 & $\begin{array}{l}\text { Reforestation of newly allocated } \\
\text { land in A Luoi-North Central } \\
\text { Vietnam }\end{array}$ & $\begin{array}{c}\text { Thua Thien Hue } \\
\text { Province }\end{array}$ & 192 & \\
\hline 5 & $\begin{array}{l}\text { Increasing the efficient use of } \\
\text { energy in brewery }\end{array}$ & $\begin{array}{l}\text { Thanh Hoa } \\
\text { province }\end{array}$ & 11 & Under consideration \\
\hline 6 & $\begin{array}{l}\text { Thu Duc power plant unit } 3 \text { fuel } \\
\text { switch from oil to gas }\end{array}$ & HCM City & 664 & Under consideration \\
\hline 7 & $\begin{array}{l}\text { Wind+ Diesel hybrid electricity } \\
\text { supply system }\end{array}$ & Binh Thuan City & 106 & Under consideration \\
\hline
\end{tabular}

Vietnam is transitioning to renewable energy sources to maintain competitive electricity generation and to deliver increased capacity quickly. Several renewable energy projects have been developed through the clean development machanism as rooftop solar project, large-scale solar project, on-shore wind power project (DEHSt, 2017).

Challenges: The awareness and knowledge of
CDM issues among managers, policy markers, experts, enterprises, general public, private sector, NGOs are still limited; The financial sources for CDM activities in country are limited; The CER price in the world is dropping; The domestic carbon trading market is still under development (UNDP Vietnam, 2018) (Nhan et al, 2010). 
Table 2. Preliminary porfolio of CDM project

\begin{tabular}{|c|c|c|c|c|}
\hline No & Name of project & Developer & Capacity & $\begin{array}{l}\text { Expected GHG } \\
\text { reduction } \\
\left(\mathrm{KT} \mathrm{CO}_{2}\right)\end{array}$ \\
\hline 1 & $\begin{array}{l}\text { Upgrading existing coal fired thermal of } \\
\text { Pha Lai power plant }\end{array}$ & Electricity of Vietnam (EVN) & $440 \mathrm{MW}$ & $378 / y$ \\
\hline 2 & $\begin{array}{c}\text { Wind power plant in Quang Tri } \\
\text { Province }\end{array}$ & QuangTri Electricity Company & $20 \mathrm{MW}$ & $129 / y$ \\
\hline 3 & $\begin{array}{c}\text { Geothermal power plant in QuangNgai } \\
\text { Province }\end{array}$ & ORMAT private & $50 \mathrm{MW}$ & $310 / y$ \\
\hline 4 & Dak Pone hydro power & RCEE & $14 \mathrm{MW}$ & $40 / y$ \\
\hline 5 & $\begin{array}{c}\text { Cogeneration for PhongKhe paper } \\
\text { village }\end{array}$ & RCEE & $6.4 \mathrm{MW}$ & $74 / y$ \\
\hline 6 & $\begin{array}{c}\text { Rice husk power plant in TienGiang } \\
\text { Area }\end{array}$ & Institute of Energy & $3 \mathrm{MW}$ & $56 / y$ \\
\hline 7 & $\begin{array}{l}\text { Improvement of oil fired boilers in } \\
\text { DongNai pulp and paper factory }\end{array}$ & Dong Nai paper factory & $\begin{array}{l}25,000 t \\
\text { paper/y }\end{array}$ & $4.3 / y$ \\
\hline 8 & $\begin{array}{l}\text { Improvement of energy efficiency in } \\
\text { Song Da cement factory }\end{array}$ & Song Da cement factory & $\begin{array}{c}85,000 \\
\mathrm{t} / \mathrm{y}\end{array}$ & $18.2 / \mathrm{y}$ \\
\hline 9 & $\begin{array}{c}\text { Efficiency of public lighting system in } \\
\text { big city }\end{array}$ & Institute of Material Science & 100,000 units & $190 / y$ \\
\hline 10 & $\begin{array}{c}\text { Advanced sedimentary brick kiln in } \\
\text { BacNinh province }\end{array}$ & Institute of Thermal Engineering & $\begin{array}{c}400 \\
\text { mill.pieces/y }\end{array}$ & $49 / y$ \\
\hline 11 & $\begin{array}{l}\text { Reforestation of newly allocated land in } \\
\text { A-Luoi district }\end{array}$ & $\begin{array}{c}\text { SNV } \\
\text { Farmer Union of ALuoi }\end{array}$ & 3,000 ha & $28 / y$ \\
\hline 12 & $\begin{array}{c}\text { Cam Lam KN Solar Power Project in } \\
\text { Viet Nam }\end{array}$ & Hanwha Energy Corporation & $50 \mathrm{MW}$ & $62 / y$ \\
\hline 13 & DaNhim-HamThuan Solar Power Plant & $\begin{array}{c}\text { DaNhim-HamThuan-DaMi } \\
\text { Hydropower Joint Stock Company } \\
\text { (DHD) }\end{array}$ & $47.5 \mathrm{MW}$ & $50 / y$ \\
\hline
\end{tabular}

Solutions: Revise and issue related legal documents to create a favorable legal framework for investors to develop and implement CDM in the country; Integrate CDM activities into national, sectoral, local development strategies and plans; Strengthen the cooperation between ministries, agencies, organizations and localities in development of CDM projects in Viet Nam; Increase the public awareness, capacity building activities on CDM; Actively assist project participants in developing the CDM projects. Create close co-operations with EB, DOE and project developers (Nhan et al, 2010) (UNDP, 2003).

\section{Conclusion}

The full extent of potential benefits available to developing countries under the CDM is difficult to forecast, but its enormous potential to promote sustainable development and increase foreign investment flows is clear. With thoughtful planning and the development of a national CDM strategy, it can also assist in addressing local and regional environmental problems and in advancing social goals. The CDM allows developing countries to participate in the global effort to combat climate change at a time when other development priorities may limit the funding available for GHG emission reduction activities. The CDM's objective of advancing the development goals of developing countries recognizes that only through long-term sustainable development will all countries be able to play a role in climate protection.

Vietnam has interested in climate change activities. Vietnam signed and ratified UNFCCC in 1994. Vietnam signed KP in 1997 and ratified it on 25 September 2002. In 1994, Vietnam issued Environment Law and Decree of Government guiding implementation of environment protection law. Vietnam would implement its commitment in International Convention on environment protection which it signed.

The UNEP Project: "Capacity Development for CDM" will contribute an important part to 
facilitating CDM activities and sustainable development in Vietnam in the future.

Acknowledgements: We thank Korea University for supporting to finalising the paper. The author thanks reviewers for their constructive comments.

\section{References}

1. DEHSt (German Emissions Trading Authority (DEHSt)), 2017. Germany's carbon market cooperation with Viet Nam: Prospects forengaging with Article 6 of the Paris Agreement.

2. Financial Policy Circular, 2007. Inter Ministrial Circular No. 58/2008/TTLT-BTCBTN\&MT "Guiding implementation of some articles under Decision No. 130/2007/QD-TTg dated 2nd August 2007 of the Prime Minister on mechanism, financial policy on CDM projects".

3. Hieu, N.K., 2003. Introduction to CDM National Authority and CDM potential projects in Viet Nam.

4. Hoang, M.H., Yen, T.T., 2014. Approval process of CDM project and PoA in Viet Nam.

5. Laurie, D., 2018. Informatics Specialist Review of CDM Code Changes Effective. Stroud water Associates.

6. MFAD (Ministry of Foreign Affairs of Denmark) 2009. CDM in Vietnam, Finance your investment and protect the environment.
7. MONRE (Ministry of Natural Resources and Environment) 2019. The third National Communication of Vietnam to the United $\mathrm{Na}$ tions Framework Convention on Climate Change.

8. Nhan, T.N., Minh, H.D., Sandra, G., Michael, M., 2010. Clean Development Mechanism in Vietnam: potential and limitations.

9. Tuan, D.D., Hieu, N.K., 2012. Implementation of UNFCCC, Kyoto Protocol and CDM in Vietnam.

10. UNDP, 2003. The Clean Development Mechanism: a User's Guide. Chapter 2:Going through the CDM Process.

11. UNDP Vietnam 2018. Opportunities for Carbon Pricing in Vietnam, Project "Strengthening Capacity and Institutional Reform for Green Growth and Sustainable Development in Viet Nam".

12. UNEP Collaborating Centre on Energy and Environment Riso National Laboratory Roskilde, Denmark, 2017. Introduction to the Clean Development Mechanism.

13. UNFCCC (United Nation Framework Convention on Climate Change) 2009. Clean development mechanism project cycle procedure.

14. UNFCCC (United Nations Framework Convention on Climate Change) 2018. Clean development Mechanism Booklet. Tenth edition Information updated as of EB 101. 